\title{
Prevalence and factors associated with Helicobacter pylori infection among treatment naïve dyspeptic adults in University of Benin Teaching Hospital, Benin City, Nigeria
}

\author{
${ }^{1}$ Odigie, A. O., ${ }^{* 2}$ Adewole, A. J., and ${ }^{2}$ Ekunwe, A. A. \\ ${ }^{1}$ Department of Family Medicine, Central Hospital, Health Management Board, Benin City, Nigeria \\ ${ }^{2}$ Department of Family Medicine, University of Benin Teaching Hospital, PMB 1111, Benin City, Nigeria \\ *Correspondence to: afolabi.adewole74@gmail.com; +2348037222755
}

\begin{abstract}
:
Background: Infectious diseases such as malaria, HIV/AIDS and tuberculosis have received tremendous attention globally but inspite of the widespread nature of infections caused by Helicobacter pylori, little attention has been paid to it especially in the developing countries. The objective of this study was to determine the prevalence of and factors associated with $H$. pylori infection among dyspeptic patients attending the University of Benin Teaching Hospital, Benin City, Nigeria.

Methodology: This was a hospital based descriptive cross-sectional study of 354 treatment naive dyspeptic patients aged 18 to 44 years, recruited consecutively after obtaining institutional ethical approval and subjects' informed consent. A pre-tested interviewer administered questionnaire was used to obtain subjects' data. The stool antigen test was used to detect $H$. pylori infection.

Results: The prevalence of $H$. pylori infection among the subject participants was $34.2 \%$ (38.4\% in female, $24.0 \%$ in male, $p=0.009)$. The age group $<20$ years had the highest prevalence of $40 \%$. Gender, occupation, increased body mass index, high number of household occupants, and rural dwelling, were significantly associated with $H$. pylori infection $(p<0.05)$ and alcohol intake was inversely related to $H$. pylori infection $(p<0.05)$.

Conclusion: The prevalence of $H$. pylori infection in University of Benin Teaching Hospital is high and factors such as gender, obesity, occupation with risk of contact, low socio-economic status, and poor hygiene, may be responsible for this.
\end{abstract}

Keywords: Dyspepsia, Helicobacter pylori, infection, stool antigen test

Received September 3, 2019; Revised November 17, 2019; Accepted November 19, 2019

Copyright 2020 AJCEM Open Access. This article is licensed and distributed under the terms of the Creative Commons Attrition 4.0 International License (http://creativecommmons.org/licenses/by/4.0), which permits unrestricted use, distribution and reproduction in any medium, provided credit is given to the original author(s) and the source.

\section{Prévalence et facteurs associés à l'infection à Helicobacter pylori chez les adultes dyspeptiques naïfs de traitement à l'hôpital universitaire de Bénin, Benin City, Nigéria}

\author{
${ }^{1}$ Odigie, A. O. ${ }^{* 2}$ Adewole, A. J., et ${ }^{2}$ Ekunwe, A. A. \\ ${ }^{1}$ Département de médecine familiale, hôpital central, Conseil de gestion de la santé, Benin City, Nigéria \\ ${ }^{2}$ Département de médecine familiale, hôpital universitaire de Bénin, PMB 1111, Benin City, Nigéria \\ *Correspondance à: afolabi.adewole74@gmail.com; +2348037222755
}

\section{Abstrait:}

Contexte: Les maladies infectieuses telles que le paludisme, le VIH / sida et la tuberculose ont fait l'objet d'une attention considérable dans le monde, mais malgré la nature généralisée des infections causées par Helicobacter pylori, peu d'attention y a été accordée, en particulier dans les pays en développement. L'objectif de cette étude était de déterminer la prévalence et les facteurs associés à l'infection à $H$. pylori chez les patients dyspeptiques fréquentant I’hôpital universitaire de Benin, à Benin City, au Nigéria. 
Méthodologie: Il s'agissait d'une étude descriptive transversale réalisée à l'hôpital auprès de 354 patients dyspeptiques naïfs de traitement, âgés de 18 à 44 ans, recrutés de manière consécutive après avoir obtenu l'approbation éthique de l'établissement et le consentement éclairé des sujets. Un questionnaire pré-testé administré par l'intervieweur a été utilisé pour obtenir les données des sujets. Le test d'antigène dans les selles a été utilisé pour détecter une infection par $\mathrm{H}$. pylori.

Résultats: La prévalence de l'infection à $H$. pylori chez les sujets était de $34,2 \%(38,4 \%$ chez les femmes, $24,0 \%$ chez les hommes, $p=0,009)$. Le groupe d'âge $<20$ ans avait la prévalence la plus élevée de $40 \%$. Le sexe, la profession, l'augmentation de l'indice de masse corporelle, le nombre élevé d'occupants et l'habitation rurale étaient significativement associés à l'infection à $\mathrm{H}$. pylori $(p<0,05)$ et la consommation d'alcool était inversement liée à l'infection à $H$. pylori $(p<0,05)$.

Conclusion: La prévalence de l'infection à $H$. pylori à l'hôpital universitaire de Bénin est élevée et des facteurs tels que le sexe, l'obésité, l'occupation avec risque de contact, le faible statut socio-économique et l'hygiène médiocre peuvent en être la cause.

Mots-clés: Dyspepsie, Helicobacter pylori, infection, test antigène dans les selles

\section{Introduction:}

Infections caused by Helicobacter pylori const itute a global health challenge with diverse consequences. Infections occur in every geographical area among different ethnic and age groups but with certain observed factors influencing their distribution. The discovery of $H$. pylori by Warren Robin (a biologist) and Marshall Barry (a clinician) in 1983 was a major breakthrough in the management of dyspepsia (1). H. pylori was first cultured from the dental plaque of a 29 year old patient in 1989 (2). This discovery had major implications in the management of dyspepsia, peptic ulcer disease and gastric cancer (3). The 2005 Nobel Prize in Physiology and Medicine was awarded to the two discoverers (4).

Dyspepsia is a common clinical problem seen by primary care physicians and gastroenterologists, and is the usual presentation of symptomatic patients infected with $H$. pylori (5), although infection may remain asymptomatic. An un-investigated dyspeptic patient may have functional (non-ulcer) dyspepsia or develop chronic active gastritis, duodenal ulcer, gastric ulcer, gastric carcinoma or gastric MALT lymphoma (5). Studies have documented a higher prevalence of $H$. pylori infection in Africa $(6,7)$, and in Nigeria, even though most data are from paediatric age groups and specialized centers, it is said to be hyper-endemic, with prevalence affected by socio-economic status, being more common in poorer sections of the society (8). Although geographical and sociodemographic prevalence of human $H$. pylori infections varies, prevalence does not parallel the incidence of morbidity caused by the infection, especially amongst Africans (9).

A number of diagnostic tests are available ranging from invasive to noninvasive. Invasive tests are performed during endoscopy with biopsy taken for histology, culture, rapid urease test, polymerase chain reaction and florescence in-situ hybridization, while non-invasive tests include serology, stool antigen test, urea breath test, salivary, and urinary antibody tests (10). The non invasive tests are important in primary care because they are cost effective, and the stool antigen test (HpSA) seems to be more promising.

The increasing incidence of $H$. pylori infection in developing countries as a result of overcrowding, low socio-economic status and poor sanitation, is particularly worse in rural and poor resource settings (11). In industrialized countries, the rate of acquisition of $H$. pylori has decreased substantially over recent decades with availability of various treatment options and higher socio-economic status (12). In Nigeria, literatures on the prevalence of $H$. pylori infection among treatment naïve dyspeptic adult patients attending primary care settings are scarce, because most studies are conducted in specialized centers where endoscopies are performed. Also, most of these studies are based on invasive methods for detection of $H$. pylori.

In Nigeria where antibiotic use is rampant (13), most patients in the specialized units are often not treatment naïve. This current study aimed to determine the prevalence of $H$. pylori infection among treatment naïve patient in a primary care setting using non-invasive method, and associated factors for $H$. pylori infection. This is to enable focused attention towards preventing its spread and eradication of the infection.

\section{Materials and methods:}

\section{Study area}

The study was carried out in the General Practice/National Health Insurance Scheme (NHIS) clinic of University of Benin Teaching Hospital, Benin City, Nigeria, tertiary 
hospital that offers both inpatient and outpatient services. The clinic is managed by the Department of Family Medicine on outpatient basis.

\section{Study design and protocol}

This was a hospital based descriptive cross sectional study. The study group consisted of 354 subjects, age range 18 to 44 years, drawn from the General Practice Clinic (GPC) and Staff/NHIS clinic. The sample size was calculated using the Leslie and Kish formula; $n=z^{2} p q / d^{2}(14)$, where ' $n$ ' is the sample size, ' $z$ ' is normal variate at $5 \%$ type 1 error, ' $p$ ' is prevalence of disease in a population from previous study, and ' $d$ ' is absolute precision with $5 \%$ error margin. Assuming a $90 \%$ response rate, the formula for adjusted non-response sample size, $\mathrm{n}_{\mathrm{s}}=$ n/0.90, gave a sample size of 393. Recruitment of subjects was done over a period of two years and 354 of 393 subjects completed the questionnaires administered in the study.

\section{Inclusion and exclusion criteria}

The inclusion criteria were subjects in age range of 18 to 44 years who were treatment naïve and had complaint of dyspepsia lasting for at least two weeks. A naïve subject was taken as any participant with dyspepsia who had not taken antibiotics in the last 4 weeks, PPIs in the last 2 weeks, and $\mathrm{H}_{2}$ receptor blockers in the last 24 hours (15). Subjects who were critically ill, pregnant or have evidence of upper gastro-intestinal bleeding were excluded.

\section{Ethical clearance}

Approval for the study was obtained from the Hospital's Ethical Committee (Protocol number: ADM/E22/A/VOL.VII/762). A written informed consent was obtained from each participant. Appropriate management was given to the participants and confidentiality was maintained throughout the study.

\section{Data collection instruments}

The data was collected using a pretested semi-structured, interviewer administered questionnaire adapted from a previously validated Dutch Gastrointestinal Symptom Questionnaire (16), as well as from questions drawn from the literature. This was modified in line with the study objectives.

The questionnaire had four sections; section $A$ assessed the demographic characteristics of the subjects including age, sex, religion, educational status, ethnicity, socio- economic status, residence, height and weight (BMI) and family size; section B identified dyspeptic symptoms in the subjects as well as duration of symptoms; section C collected information on associated factors for $H$. pylori infection, such as number of household occupants, number of room occupants, and past sources of drinking water, as well as duration of symptoms, smoking and alcohol consumption. Household occupants were taken as number of persons living in a house, room occupants were taken as number of person sharing a room, smoking status was taken as present smokers, past smokers or never smoked cigarette, alcohol consumption was taken as current consumption of beer, wines, whisky or local gin. Past sources of water was taken as sources of water during subjects childhood days, family size was taken as $\leq 4$ children or $>4$ children. Section $D$ was for determination of the presence of $H$. pylori in the subjects stool samples using $H$. pylori stool antigen test (HpSA).

\section{Measurement of weight, height and body mass index}

The weight and height of each subject were measured free from pocket objects, wristwatch, jewelries, shoes, and head dressing using a mechanical weighing and height scale (RGZ-160; Shanghai Maney Medical Technical Ltd, China). The BMI was calculated for each subject using the formula: BMI $\left(\mathrm{kg} / \mathrm{m}^{2}\right)=\mathrm{w} / \mathrm{h}^{2}$, where ' $\mathrm{w}$ ' is weight in $\mathrm{kg}$ and ' $h$ ' is height in metres. They were classified using the World Health Organization's classification of obesity (17). Obesity was taken as BMI greater than or equal $30 \mathrm{~kg} / \mathrm{m}^{2}$, overweight was regarded as BMI between 25 and $29.9 \mathrm{~kg} / \mathrm{m}^{2}$, while normal weight was taken as BMI between 18.5-24.9 kg/m² and underweight as BMI less than $18.5 \mathrm{~kg} / \mathrm{m}^{2}$.

\section{Stool antigen test for $\boldsymbol{H}$. pylori.}

A commercial validated Stool Antigen Test kit, Bioline SD Rapid Test (Standard Diagnostics, Inc, Lot number 164006, cat number 04FK20) was used. The test is based on immunochromatographic principle with the test kit impregnated with antibodies specific to $H$. pylori antigen in human faecal specimens. The kit, as indicated by the manufacturer, has specificity of $91.9 \%$ and sensitivity of $92.4 \%$ compared to $H$. pylori stool culture as 'gold standard'.

Stool antigen test, according to the manufacturers' instructions, was done within 24 hours of sample collection. The test was performed by a laboratory scientist trained 
during the pilot test, during which inter-rater reliability was assessed and confirmed. A sterile swab stick from the stool kit was used to collect faeces from the container, which was then inserted into the sample collection tube containing the assay diluents. The swab stick was swirled about 10 times inside the diluents until the stool sample dissolved. The sample collection tube was capped and left for about 5 minutes. Three drops of prepared stool sample was placed in the sample well of the test device and result interpreted in 15 minutes. Two red lines showing control (C) and test ( $\mathrm{T}$ ) on the test kit indicate positive while a single red line showing control indicates negative result. Result is indeterminate if there is no line or only $\mathrm{T}$ line, in which case the test is repeated.

\section{Data management and analysis}

Data were checked for completeness and consistency, and then analysed using the Statistical Package for Social Sciences (SPSS version 16.0, Chicago Illinois). Results were presented as percentages and tables. Pearson's Chi square test was used to compare association between prevalence of $H$. pylori infection and socio-demographic variables as well as associated factors. Risk estimate odds ratio was also used to test the association between gender and risk of $H$. pylori infection, and $p$ value less than 0.05 was considered significant.

\section{Results:}

Sociodemographic characteristics of subjects and $H$. pylori infection

As shown in Table 1, a total of 354 subjects were studied; $59.9 \%$ were in age range of 40-49 years, 104 (29.4\%) males, and $250(70.6 \%)$ females (M: F ratio of $1: 2.4)$. Of the 354 subjects, 121 were positive for $H$. pylori by the stool antigen test, given a prevalence rate of $34.2 \%$. The prevalence was significantly higher in females $(38.4 \%)$ than males $(24.0 \%)(p=0.009)$. Although most of the subjects in this study were unskilled $(53.7 \%)$, the prevalence of $H$. pylori infection was significantly higher among professionals $(87.5 \%)$ than among unskilled and other categories of subjects $(p=0.009)$. The prevalence of $H$. pylori infection was also significantly higher in obese (61.1\%) and overweight $(37.0 \%)$ than normal weight subjects $(16.5 \%)$ $(p<0.001)$. Although, majority of the subjects $(78.5 \%)$ resided in urban centers, the prevalence of $H$. pylori infection was significantly higher in rural dwellers $(48.7 \%)$ than in subjects from urban areas $(30.2 \%)(p=0.003)$.

There were no significant differences in the prevalence of $H$. pylori infections with respect to age groups $(p=0.313)$, marital status $(p=0.168)$, socioeconomic status $(p=0.142)$, ethnicity $(p=0.611)$, religion $(p=0.520)$ and level of education $(p=0.266)$.

Factors associated with $\boldsymbol{H}$. pylori infection Table 2 shows that subjects whose number of household occupants ranged from 1 to 5 persons had $H$. pylori prevalence of $29.5 \%$, which was significantly lower than $39.6 \%$ in subjects whose occupants were above $5(p=0.044)$. The prevalence of $H$. pylori infection was also significantly higher in subjects who do not consume alcohol (38.3\%) than in subjects who consume less than 3 units of alcohol (33.6\%) and those who consume more than 3 units $(18.6 \%)$ of alcohol $(p=0.049)$.

There was no significant difference in the prevalence of $H$. pylori infections between subjects who had one roommate (33.6\%) and those who had more than one roommate $(36.0 \%)(p=0.683)$. Similarly, there were no significant differences in the prevalence of $H$. pylori infections with respect to past sources of water $(p=0.210)$. Though not statistically significant $(p=0.124)$, the prevalence of $H$. pylori infection was lower in cigarette smokers $(21.9 \%)$ than non smokers $(35.4 \%)$. 
Table 1: Socio-demographic and clinical characteristics of subjects in relation to $H$. pylori infection

\begin{tabular}{|c|c|c|c|c|c|}
\hline Variables & $\begin{array}{c}\text { No of subjects } \\
\quad(n=354)\end{array}$ & $\begin{array}{c}\text { No positive (\%) } \\
(n=121)\end{array}$ & $x^{2}$ & $95 \% \mathrm{CI}$ & $p$ value \\
\hline \multicolumn{6}{|l|}{ Gender } \\
\hline Male & 104 & $25(24.0)$ & 6.733 & $1.175-3.303$ & 0.009 \\
\hline Female & 250 & $96(38.4)$ & & & \\
\hline \multicolumn{6}{|l|}{ Age group (years) } \\
\hline$<20$ & 5 & $2(40.0)$ & 3.563 & $0.309-0.409$ & 0.313 \\
\hline $20-29$ & 65 & $16(24.6)$ & & & \\
\hline $30-39$ & 72 & $28(38.9)$ & & & \\
\hline $40-49$ & 212 & $75(35.4)$ & & & \\
\hline \multicolumn{6}{|l|}{ Marital status } \\
\hline Single & 75 & $21(28.0)$ & 5.052 & $0.151-0.233$ & 0.168 \\
\hline Married & 224 & $78(34.8)$ & & & \\
\hline Widowed & 44 & $20(45.5)$ & & & \\
\hline Separated/divorced & 11 & $2(18.2)$ & & & \\
\hline \multicolumn{6}{|l|}{ Occupation } \\
\hline Professional & 8 & $7(87.5)$ & 13.620 & $0.000-0.013$ & 0.009 \\
\hline Skilled & 39 & $9(23.1)$ & & & \\
\hline Semi-skilled & 44 & $12(27.3)$ & & & \\
\hline Unskilled & 190 & $69(36.3)$ & & & \\
\hline Unemployed & 73 & $24(32.9)$ & & & \\
\hline \multicolumn{6}{|l|}{ Socioeconomic status } \\
\hline High & 55 & $19(34.5)$ & 3.901 & & 0.142 \\
\hline Middle & 120 & $33(27.5)$ & & & \\
\hline Lower & 179 & $69(38.5)$ & & & \\
\hline \multicolumn{6}{|l|}{ Body mass index } \\
\hline Normal weight & 91 & $15(16.5)$ & 25.07 & $0.000-0.008$ & $<0.001$ \\
\hline Over weight & 227 & $84(37.0)$ & & & \\
\hline Obese & 36 & $22(61.1)$ & & & \\
\hline \multicolumn{6}{|l|}{ Ethnicity } \\
\hline Bini & 171 & $60(35.1)$ & 3.580 & $0.594-0.694$ & 0.611 \\
\hline Esan & 53 & $20(37.7)$ & & & \\
\hline Etsakor & 26 & $10(38.5)$ & & & \\
\hline Igbo & 62 & $20(32.3)$ & & & \\
\hline Yoruba & 15 & $2(13.3)$ & & & \\
\hline Others & 27 & $9(33.3)$ & & & \\
\hline \multicolumn{6}{|l|}{ Religion } \\
\hline Christianity & 314 & $106(33.8)$ & 2.239 & $0.522-0.625$ & 0.524 \\
\hline Islam & 19 & $5(26.3)$ & & & \\
\hline Traditional religion & 19 & $9(47.4)$ & & & \\
\hline Other religion & 2 & $1(50.0)$ & & & \\
\hline \multicolumn{6}{|l|}{ Level of education } \\
\hline No formal & 83 & $34(41.0)$ & 3.963 & $0.260-0.356$ & 0.266 \\
\hline Primary & 96 & $35(36.5)$ & & & \\
\hline Secondary & 118 & $33(28.0)$ & & & \\
\hline Tertiary & 57 & $19(33.3)$ & & & \\
\hline \multicolumn{6}{|l|}{ Subjects' residence } \\
\hline Rural & 76 & $37(48.7)$ & 9.049 & & 0.003 \\
\hline Urban & 278 & $84(30.2)$ & & & \\
\hline
\end{tabular}


Table 2: Factors associated with $H$. pylori infections in treatment naïve dyspeptic patients in University of Benin Teaching Hospital

\begin{tabular}{|c|c|c|c|c|c|}
\hline Variables & $\begin{array}{l}\text { No of subjects } \\
(n=354)\end{array}$ & $\begin{array}{c}\text { No positive (\%) } \\
(n=121)\end{array}$ & $x^{2}$ & $95 \% \mathrm{CI}$ & $p$ value \\
\hline \multicolumn{6}{|l|}{ Household occupants } \\
\hline 1-5persons & 190 & $56(29.5)$ & 4.039 & & 0.044 \\
\hline $\begin{array}{c}>5 \text { persons } \\
\text { Number of roommates }\end{array}$ & 164 & $65(39.6)$ & & & \\
\hline $\begin{array}{c}1 \text { roommate } \\
>1 \text { roommate } \\
\text { Past sources of water }\end{array}$ & $\begin{array}{c}265 \\
89\end{array}$ & $\begin{array}{l}89(33.6) \\
32(36.0)\end{array}$ & 0.166 & & 0.683 \\
\hline $\begin{array}{l}\text { River } \\
\text { Stream } \\
\text { Water tanker } \\
\text { Well } \\
\text { Bore hole } \\
\text { Tap water } \\
\text { Rain water } \\
\text { Smoking of cigarettes }\end{array}$ & $\begin{array}{c}93 \\
30 \\
3 \\
84 \\
10 \\
91 \\
43\end{array}$ & $\begin{array}{c}29(31.2) \\
7(23.3) \\
0 \\
35(41.7) \\
2(20.0) \\
36(39.6) \\
12(27.9)\end{array}$ & 8.408 & $0.146-0.227$ & 0.210 \\
\hline Yes & 32 & $7(21.9)$ & 2.368 & & 0.124 \\
\hline No & 322 & $114(35.4)$ & & & \\
\hline \multicolumn{6}{|l|}{ Alcohol consumption } \\
\hline Non consumers & 180 & $69(38.3)$ & 6.037 & & 0.049 \\
\hline$\leq 3$ units & 131 & $44(33.6)$ & & & \\
\hline > 3units & 43 & $8(18.6)$ & & & \\
\hline \multicolumn{6}{|l|}{ Duration of symptoms } \\
\hline$\leq 6$ months & 98 & $28(28.6)$ & 1.895 & & 0.169 \\
\hline$>6$ months & 256 & $93(36.3)$ & & & \\
\hline
\end{tabular}

\section{Discussion:}

This study aimed at determining the prevalence of $H$. pylori and factors associated with infection caused by this bacterium in treatment naïve dyspeptic patients attending primary care unit of a tertiary hospital in Nigeria. We report a high prevalence of $34.2 \%$ using stool antigen test, which agrees with a similar study by Smith et al., in southwest Nigeria (18), although this was done in a tertiary healthcare referral center with facility for endoscopy compared to our present study in a primary care setting. This further confirmed the high prevalence of $H$. pylori infection regardless of the level of care. Also, Yucel et al., (19) reported a high prevalence of $H$. pylori among students who were not classified as dyspeptic, as distinct from our current study on dyspeptic patients. This confirms that high prevalence of $H$. pylori infection occurs in both symptomatic and asymptomatic populations.

However, reports of other studies that determined $H$. pylori infection by other methods $(20,21,22,23,24)$ aside from stool antigen test are at variance with our study. Most of these studies were conducted in healthcare centers with endoscopic facility for invasive procedures, and these centers tend to receive patients referred from primary care setting following unresolved dyspeptic symptoms after empirical treatment. One of the criteria for referrer of dyspeptic patients is unresolved symptoms following treatment (25).

The prevalence of $H$. pylori infection in our study was significantly higher in females. A number of studies have reported that female gender had higher prevalence than males with odds ratio of 1.97. Tanih et al., (26) in South Africa using histological method reported significantly higher prevalence in females $(69.5 \%)$ compared to males $(60.0 \%)$. Most females from our present study were market women with higher tendency for indiscriminate eating habit and poor hygiene. This is critical as they may eventually become carriers and a host for the spread of $H$. pylori infection. However, a meta-analysis involving 18 
different adult population studies by Martel et al., (27) showed that male gender was significantly associated with $H$. pylori infection, even though some of the individual studies showed otherwise. Another study by Ugwuja et al., (11) from Abakaliki, Nigeria, showed that the prevalence of $H$. pylori infection was similar in males (28\%) and females (25\%).

Similar to findings from other studies, the prevalence of $H$. pylori was significantly higher among respondents living in rural settlements and those with high number of household occupants. Gunaid et al., (28) reported higher prevalence of $H$. pylori infection among family whose size is equal or greater than 6 members. Similarly, Santos et al, (29) found a higher prevalence of $69.7 \%$ in families with more than 4 children or relatives as compared to $58.5 \%$ in families with less than 4 children or relatives. Rural dwelling in our study area is typified by overcrowding and poor hygiene as found in other developing countries, which is at variance with rural settings from developed countries (30). This suggests that a higher number of persons per household may increase infection transmission rate. A similar association was seen in the study by Aguemon et al., (30) in which subject participants with 1 roommate and those with 2 or 3 roommates had a prevalence of $51.0 \%$ and $77.6 \%$ respectively. This present study further supports the notion that $H$. pylori infection is a disease of overcrowding and poor hygiene.

In our study, the prevalence of $H$. pylori infection was associated with body mass index (BMI), with obese and overweight patients having significantly higher prevalence than normal weight patients. This agrees with the study by Al-Akwaa (31) in Saudi Arabia, which showed high $H$. pylori prevalence of $85.5 \%$ in a group of morbidly obese Saudi patients. The reason for this may be bidirectional as persons with dyspepsia from $H$. pylori infection may eat more frequently, in order to alleviate dyspeptic symptoms, and so are more likely to become overweight. On the other hand, obese people may be less discriminatory of where they eat. This may impact on the food hygiene, predisposing them to $H$. pylori infection. However, many studies in children and adult populations have shown that $H$. pylori infection is not associated with BMI or overweight $(32,33,34)$.

Although most studies have found no significant relationship between occupation and $H$. pylori infection, our study showed a high prevalence of $H$. pylori infection of $87.5 \%$ among professionals (majority are health workers), which was significantly different from other occupational groups. Some studies have shown various pathways of agent transmission, favoring person-to-person transmission early in life, and oro-oral, faeco-oral and gastro-oral transmission have been proposed $(35,36)$. Our finding supports possible person-to-person mode of spread of $H$. pylori infection among health workers hence the need for implementation of standard precautions among high risk professionals.

Studies on association of alcohol consumption and $H$. pylori infection are conflicting however, our study showed low prevalence of $H$. pylori infection among subjects who consume alcohol. This may suggest that dyspepsia, which is common among alcoholics, may be more of functional origin than $H$. pylori infection related. Some studies have shown that alcohol has an antibacterial effect against $H$. pylori and the increase in acid secretion caused by alcohol has a bactericidal effect. While this may explain the inverse association between $H$. pylori infection and alcohol $(37,38)$, others have found no significant association $(39,40)$. The effects of alcohol on $H$. pylori infections require further research.

\section{Conclusion:}

The prevalence of $H$. pylori infection in treatment naïve dyspeptic patients in our area is high. Gender and factors related to poor hygiene, increase faeco-oral transmission, and low socio-economic status are related to the high prevalence. Alcohol consumption was inversely related to $H$. pylori infection hence dyspepsia among subjects who consume alcohol needs to be thoroughly investigated, as organic origin might be responsible. Consequently the test and treat approach as recommended by the European Helicobacter pylori group; Maastricht 111 (updated in 2005) is invaluable in our environment. Improving personal hygiene remains an efficient means of curtailing the menace of $H$. pylori infections and the attendant sequelae.

\section{References:}

\footnotetext{
1. Talley, N. J., and Vakil, N. Guidelines for the management of dyspepsia. Am J Gastroenterol. 2005; 100 (10): 2324-2337

2. Assumpcao, M. B., Martins, L. C., Barbosa, H. P. M., et al. Helicobacter pylori in dental plaque and stomach of patients from Northern Brazil. World ] Gastroenterol. 2010; 16 (24): 3033-3039

3. Flahault, A., and Tulchinsky, T. H. Preface to reminiscences on Helicobacter pylori. Public Health Rev. 2010; 32 (1): 7-9
} 
4. Normark, S. Presentation Speech of the Nobel Prize for Physiology or Medicine, 2005 on behalf of the Nobel Foundation, Karolinska Institute. December 10, 2005:

http://nobelprize.org/nobelprizes/medicine/laureates/200 5/presentation-speech-html.

5. Harmon, R. C., and Peura, D. A. Evaluation and Management of Dyspepsia. Therap Adv Gastroenterol. 2010; 3 (2): 87-98

6. Asrat, D., Nilsson, I., Mengistu, Y., et al. Prevalence of Helicobacter Pylori VacA and Cag A genotypes in Ethiopian dyspeptic patient. J Clin Microbiol. 2004; 42 (6): 2682-2684

7. Nwodo, E. N., Yakubu, S. E., Jatau E. D., and Yabaya, A. Seroprevalence of Helicobacter pylori infection in patients with gastritis and peptic ulcer disease in Kaduna, Kaduna State, Nigeria. African J Basic Appl Sci. 2009; 1 (5-6): 123-12

8. Etukudo, O. M., Ikpeme, E. E., and Ekanem, E. E. Seroepidemiology of Helicobacter pylori infection among children seen in a tertiary hospital in Uyo, Southern Nigeria. Pan Afr Med J. 2012; 12: 39

9. Ndip, R. N., Malange, A. E., Akoachere, F. T., et al. Helicobacter antigens in faeces of asymptomatic children in the Buea and Limbe health district of Cameroon: A Point Study. Trop Med Int Health. 2004; 9 (9): 1036 - 1040

10. Maria, P. D., Giovanni, M. P., Gabrio, B., and Paolo, U. Dyspepsia: When and How to Test for Helicobacter pylori Infection. Gastroenterol Res Pract. 2016; 2016: 8463614

11. Ugwuja, E. I., and Ugwu, N.C. Helicobacter pylori in uninvestigated dyspepsia in primary cares in Abakaliki, Nigeria. OJHAS. 2007; 6(1): 1-4

12. Genta, R. M. Review article: after gastritis-an imaginary journey into a Helicobacter-free world. Aliment Pharmacol Ther. 2002; 16 (Suppl. 4): 89-94

13. Lorina, I., B., Promise, M., E., and Michael, 0 Evaluation of the extent and reasons for increased non-prescription antibiotics use in a University town, Nsukka Nigeria. Int J Health Sci (Qassim). 2018; 12 (4): 11-17

14. Araoye, M. O. Research methodology with statistics for health and social sciences. In: Araoye M. O (ed). $1^{\text {st }}$ edition. Subject Selection. Nathadex Publishers, Ilorin, Kwara State 2008: 118-122

15. Stone, M. A., Barnett, D. B., and Mayberry, J. F. Lack of correlation between self-reported symptoms of dyspepsia and infection with Helicobacter pylori, in a general population sample. Eur J Gastroenterol Hepatol. 1998; 10 (4): 301-304

16. Bovenschen, H. J., Janssen, J. R., Van Oijen, G. $\mathrm{H}$., et al. Evaluation of a gastrointestinal system Questionnaires. Dig Dis Sci. 2006; 51: 1509-1515

17. Mbada, C. E., Adedoyin, R. A., and Odejide, A. S. Relationship between socio-economic status and body mass index among adult Nigerians. AJPRS. 2009; 1 (1): 1-6

18. Smith, S. I., Omonigbehin, E. A., Goodluck, H. H., and Abdulkareem, F. B. Diagnostic methods for the detection of Helicobacter pylori in Nigeria. Trop Gastroenterol. 2010; 31(2):113-115

19. Yucel, T., Aygin, D., Sen, S., et al. The Prevalence of Helicobacter pylori and related factors among University Students in Turkey. Jpn J Infect Dis. 2008; 61 (4): 331

20. Asfeldt, A. M., Lochen, M. L., Straume, B., et al. Accuracy of a monoclonal antibody based stool antigen test in the diagnosis of Helicobacter pylor infection. Sci J Gastroenterol. 2004; 39 (11): 1073-1077

21. Alamzi, W. M., Saddique, I., Alateegi, N., and AlNakib, B. Prevalence of Helicobacter pylori infection among new outpatients with dyspepsia in
Kuwait. BMC Gastroenterol. 2010; 10: 14 Adeniyi, B. A., Otegbayo, J. A., Lawal, T. O., et al. Prevalence of Helicobacter Pylori infection among dyspepsia patients in Ibadan, South West Nigeria. Afr J Microbiol Res. 2012; 6 (14): 3399-3402 23. Segal, I., Otley, A., Issenman, R., et al. Low prevalence of Helicobacter pylori infection in Canadian children: a cross sectional analysis. Can J Gastroenterol. 2008; 22 (5): 485-489

24. Oluwasola, A. O., Otegbayo, J. A., Ola, S. O., et al. Correlation of serum anti-Helicobacter pylori immunoglobulin A (IgA) with histological parameters of chronic gastritis in Ibadan, Nigeria. Annals of Ibadan Postgraduate Medicine. 2012; 10 (1): 18-24

25. Paul, M. M., Brian, E. L., Christopher, N. A., Robert, A. E., Colin, W. H., and Nimish, V. ACG and CAG Clinical Guideline: Management of Dyspepsia. Am J Gastroenterol. 2017; 112: 9881013

26. Tanih, N. F., Okeleye, B. I., Ndip, L. M., et al. Helicobacter Pylori prevalence in dyspeptic patients in the Eastern Cape Province race and disease status. S. Afr Med J. 2010; 100 (11): 734737

27. Martel, C., and Parsonnet, J. Helicobacter pylori infection and gender: a meta-analysis of population-based prevalence surveys. Dig Dis Sci. 2006; 51 (12): 2292-2301

28. Gunaid, A. A., Hassan, N. A., and Murray-Lyon, I. Prevalence and risk factors for Helicobacter pylori infection among Yemeni dyspeptic patients. Saudi Med J. 2003; 24 (5): 512-517

29. Santos, I. S., Boccio, J., Santos, A. S., et al. Prevalence of Helicobacter pylori infection and associated factors among adults in southern Brazil: a population-based cross sectional study. BMC Publ HIth. 2005; 5: 118

30. Aguemon, B. D., Struelens, M. J., Massougbodji, A., and Ouendo, E. M. Prevalence and risk factors for Helicobacter pylori infection in urban and rural Beninese populations. Clin Microbiol Infect. 2005; 11 (8): 611-617

31. Al-Akwaa, A. M. Prevalence of Helicobacter pylori infection in a group of morbidly obese Saudi patients undergoing bariatic surgery: a preliminary report. Saudi J Gastroenterol. 2010; 16 (4): 264-267

32. Ioannou, G. N., Weiss, N. S., and Kearney, D. J. Is Helicobacter pylori seropositivity related to body mass index in the United States? Aliment Pharmacol Ther. 2005; 21:765-72

33. Cho, I., Blaser, M. J., François, F., et al. Helicobacter pylori and overweight status in the United States: data from the Third National Health and Nutrition Examination Survey. Am J Epidemiol. 2005; 162: 579-584

34. Xu, M. Y., Liu, L., Yuan, B. S., Yin, J., and Lu, Q. B. Association of obesity with Helicobacter pylori infection: a retrospective study. World J Gastroenterol. 2017; 23 (15): 2750 - 2756

35. Mégraud, F. Transmission of Helicobacter pylori: faecal-oral versus oral-oral route. Aliment Pharmacol Ther. 1995; 9 (suppl 2): 85-91

36. Oderda, G. Transmission of Helicobacter pylori infection. Can J Gastroenterol. 1999; 13:595-597

37. Ogihara, A., Kikuchi, S., Hasegawa, A., et al. Relationship between Helicobacter pylori infection and smoking and drinking habits. J Gastroenterol Hepatol. 2000; 15: 271-276

38. Murray, L. J., Lane, A. J., Harvey, I. M., et al. Inverse relationship between alcohol consumption and active Helicobacter infection: the Bristol Helicobacter project. Am J Gastroenterol. 2002; 97: $2750-2755$ 
39. Rosenstock, S. J., Jorgensen, T., Andersen, L. P., et al. Association of Helicobacter pylori infection with lifestyle, chronic disease, body indices, and age at menarche in Danish adults. Scand J Public Health. 2000; $28: 32-40$
40. Moayyedi, P., Axon, A. T., Feltbower, R., et al., and the Leeds HELP Study Group. Relation of adult lifestyle and socioeconomic factors to the prevalence of Helicobacter pylori infection. Int J Epidemiol. 2002; 31: 624-631 